\title{
MULTIPLIER EFFECTS IN LOCAL AND REGIONAL DEVELOPMENT
}

\author{
BoleSŁaW DomańSKi \& KRZYSZTOF GwOSDZ \\ Institute of Geography and Spatial Management, Jagiellonian University, \\ Cracow, Poland \\ Manuscript received May 12, 2010 \\ Revised version June 7, 2010
}

DomańsKi B. \& Gwosdz K., Multiplier effects in local and regional development. Quaestiones Geographicae 29(2), Adam Mickiewicz University Press, Poznań 2010, pp. 27-37, 1 Fig. ISBN 978-83-232-2168-5. ISSN 0137-477X. DOI 10.2478/v10117-010-0012-7.

\begin{abstract}
The aim of the paper is to outline demand-driven multiplier mechanisms, the theory behind them, and applicable quantification methods (aggregate models and incremental methods). The authors discuss a number of key problems related to multiplier effects as fundamental mechanisms of local and regional development. The study of the magnitude, industry structure, spatial distribution, and key determinants of those effects can help understand growth mechanisms in local and regional economies and evaluate the advantages and disadvantages associated with new, e.g. foreign, investment. Furthermore, the results of earlier empirical studies of the magnitude, spatial distribution and determinants of multiplier effects are presented together with the outcomes of the authors' own study.
\end{abstract}

KEYWORDS: multiplier effects, local and regional development

Bolestaw Domański, Institute of Geography and Spatial Management, Jagiellonian University, ul. Gronostajowa 7, 30-387 Krakow, Poland, e-mail: boleslaw.domanski@uj.edu.pl

Multiplier effects are one of the fundamental mechanisms of localand regionaldevelopmentand occur when one type of economic activity affects another. Multiplier effects are driven primarily by market forces. An increase (or decrease) of one type of economic activity in a given city or region prompts an increase (or decrease) in demand for goods and services, which then triggers the development of other types of economic activity in the same region or city. An increase (or decrease) in income or employment in a local or regional economy triggered by the emergence of a new type of economic activity is called a multiplier effect. The multiplier is an attempt to quantify the power of a given economic trigger.
The aim of the paper is to outline demand-driven multiplier mechanisms, the theory behind them, and applicable quantification methods. The authors discuss a number of key problems associated with multiplier effects in the context of local and regional development. Furthermore, they show selected trends identified empirically.

\section{Theory behind multiplier effects}

Multiplier effects are part of several different theoretical approaches to urban and regional development, including the following: 
- economic base theory,

- input-output model,

- growth pole theory.

Economic base theory and its close relative, export base theory, can be used to explain the development of a city or region in terms of economic activities satisfying external demand, which assumes a dependence on broader markets. The activities of this type constitute the economic base of the city or region. Other forms of economic activity - those that serve the internal needs of the city or region (endogenous activity) - are a function of the economic activity that constitutes the economic base (exogenous activity). The relationship between total economic activity and the economic base - often thought of in terms of employment - is expressed by a local/ regional multiplier that allows an assessment of the impact of changes in the economic base on the entire economy of the city or region. Multipliers were used to forecast the impact of changes in the economic base on future employment and population of cities and regions (Hoyt 1949; Alexander 1954).

The input-output model takes a more refined approach; it is not based on a division of the local and regional economy into just two sectors. The model attempts to show the linkages between many different types of economic activity in a given city or region. An input-output matrix is used to calculate input coefficients, which measure inputs necessary to generate the output of each economic activity. Input coefficients, together with the degree to which demand is met locally or regionally, allow an analysis of the impact of changes in one sector of the economy on other sectors in the city or region (multiplier effects). This type of analysis is normally part of what has been termed regional science (Isard 1960; Miller \& Blair 1985). Input-output analysis also allows a consideration of inter-regional linkages (multipliers).

Multiplier effects also play a very important role in growth pole theory. The theory rests on the idea that dynamic economic activity impacts local and regional economies and multiplier effects are the basic mechanism whereby a growth pole affects its surroundings.

It should also be noted that strong locally confined multiplier effects are a basic force exerted by metropolitan areas.

\section{How do the multiplier effects work?}

Demand-driven multiplier effects are the most important. In terms of microeconomics, the multiplier effect of the arrival of a new company or an increased level of activity by an existing Company $X$ is an increase in income and employment at other companies in the geographic area. This is caused by increased demand generated by the new company or the increased level of activity of Company $X$.

Two basic types of demand-driven multiplier effects have been identified: a supply type and an income type.

Supply-side effects arise when additional demand is generated by new or growing business enterprises, which enables their suppliers to grow as well. Income-type effects are the result of the increased purchasing power of households driven by wages and salaries offered by growing enterprises, which allows providers of consumer products to grow as well. The growth of one company or several companies multiplies the economic benefits in a given area by helping to drive the growth of other business entities. The businesses involved, in turn, generate increased demand for goods and services, which initiates another cycle of multiplier effects. Such 'second-order' effects prompt third-order multiplier effects, fourth-order multiplier effects, and so on. The magnitude of each subsequent multiplier effect is increasingly smaller, which means that the number of iterations necessary to estimate the total multiplier effect is finite. Moreover, business growth increases tax revenue for local governments, which may be used to improve local infrastructure and public services (Fig. 1).

In the economic literature, a stimulus in the form of an increase in a certain type of activity is known as a direct effect, supply-side effects are also known as indirect effects, and income-type effects are known as induced effects.

The impact of an increase of certain types of economic activity on the local or regional economy does not end with demand-driven multiplier effects. Another effect may be an influx of companies that are customers of expanding business enterprises (forward linkages). Yet another effect may be an increase in the level of economic activity and innovation in a city or 


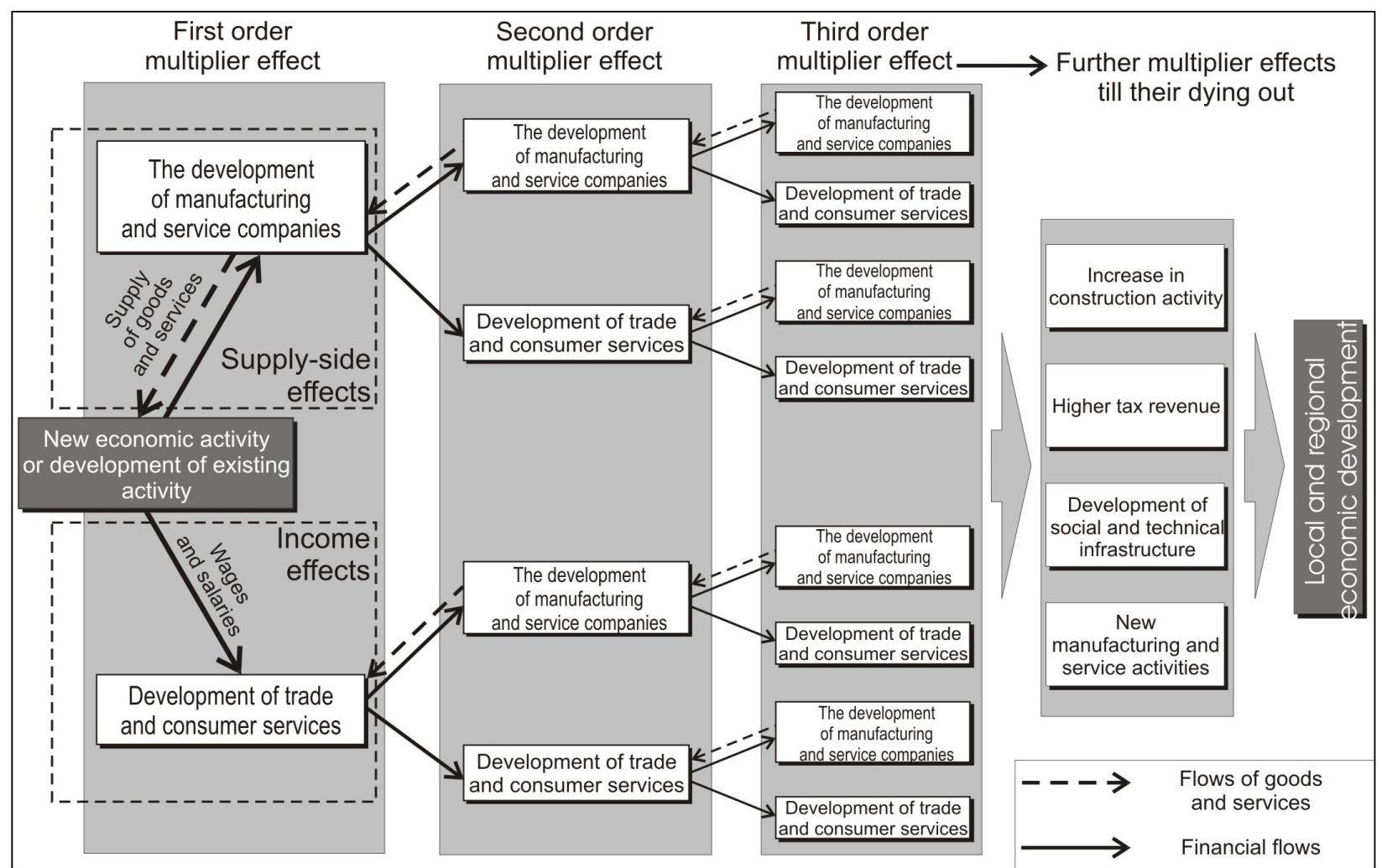

Fig. 1 Mechanism of supply-side and income-type multiplier effects Source: Domański et al. (2005), Fig. 18 with modifications

region resulting from the improvement of its image and "follower effects" (Lloyd \& Dicken 1977). In the long run, real-estate values may rise and increase income levels for both local residents and governments.

Multiplier effects generated by the creation of a new type of economic activity in a given area, for example a large new manufacturing facility, are of particular interest. Ultimately, multiplier effects resulting from any change in economic activity in a given area are important, regardless of when it started.

One must not forget that multiplier effects may produce not only positive outcomes but also negative ones. Reductions in output and the liquidation of companies lead to lower incomes and lower employment at suppliers as well as business entities serving the needs of the employees made redundant.

It is important to consider a number of fundamental research issues associated with local and regional multiplier effects.

The most important general issue is the total magnitude of multiplier effects generated by an increase in economic activity or the creation of a new type of economic activity in a given city or region. This leads to another important question: Are supply-side or income effects stronger?

Another interesting feature is the industry distribution of multiplier effects - some industries experience stronger effects than others. This issue can be analysed by comparing multiplier effects in the manufacturing sector and the service sector as well as by looking at specific services and types of manufacturing activity. Differences in the magnitude of multiplier effects between different economic activities suggest that such effects produce structural changes in local and regional economies.

From a geographical point of view, the salient question is: where do multiplier effects begin and what is their spatial range? Multiplier effects include the growth of local enterprises as well as the development of suppliers of goods and services located in distant regions, and even abroad. The more contained multiplier effects in a city or region, the stronger their impact on the given city or region as drivers of cumulative 
economic growth. On the other hand, the 'trickling' of multiplier effects into areas outside of the city/ region in question in the form of the purchase of goods and services positively affects such fringe areas. Thus, a multiplier effect spreads out away from its point of origin, e.g. a growth pole.

The fundamental issues to be considered are the magnitude of multiplier effects and their industry distribution as well as their spatial distribution. The factors that determine the evolution of multiplier effects are a core issue of interest as well.

\section{Methods of measuring multiplier effects}

The theoretical approaches described earlier suggest two basic means of measuring multiplier effects: 1) an aggregate method, and 2) an incremental method.

The most basic of multiplier-effectcalculations rest on economic base theory and consist of a comparison of total economic activity in a city (or region) and its economic base. Multipliers may be estimated based on regression models using a multi-city/region sample or a single city/ region for a longer period of time. This type of calculation is usually based on employment data and is easier to carry out than a calculation based on the incremental method. The most difficult part of the aggregate method is classifying business activity in a city or region either as economicbase type (exogenous) or supplemental type (endogenous). This type of approach, however, does not allow an assessment of the influence of an economic stimulus such as growth in a particular local or regional industry. Aggregate multipliers calculated in this manner are technically not in agreement with the theoretical understanding of multiplier effects as increases (or decreases) in economic activity resulting from increases (or decreases) in demand for goods and services on the part of other industries in a given city or region.

The proper way to measure multiplier effects is to estimate incremental changes in a particular industry and then assess changes in the overall economic activity level in a given geographic area. This type of measurement is much more difficult to carry out than an aggregate measurement, as it requires the acquisition of a wide array of interindustry and inter-company data.

Two basic types of measures of multiplier effects are used: 1) number of jobs, and 2) business revenue. The number of jobs is used more often than business revenue in multiplier effect analysis as it seems more convincing. Some research has also been done in order to calculate multiplier effects with respect to value added, for example, gross domestic/regional product at a regional level. A similar attempt has been made with respect to personal income.

Multiplier effects can be measured at an industry level or a single company/plant level. Existing general models of inter-industry linkages (input-output) or company surveys may be used.

Examples of advanced American-produced tools used to measure multiplier effects include RIMS II, IMPLAN, and REMI. The first two are based on input-output analysis - specifically Leontief's inverse matrix. The database used to calculate multiplier effects includes inter-industry linkages for each model for a total of 500 types of economic activity. The input-output data are acquired from a number of government sources including the U.S. Bureau of Economic Analysis. The IMPLAN (IMpact Analysis for PLANning) Model has been in development since the 1980s and today is available in the form of commercial software. It enables the calculation of multiplier effects at every level from local (county) to national (USA) (Propst 2000). The simulation-type REMI (Regional Economic Model) Model is also available in the form of commercial software. It is known as an eclectic model, as it calculates multiplier effects based on the input-output matrix combined with the Cobb-Douglas econometric model. It allows the anticipation of changes in costs, pay levels, and productivity (Lynch 2000). Rickman \& Schwer (1995) compared multipliers calculated using the three models listed above and concluded that the differences between the results were usually statistically insignificant. They found that the IMPLAN Model tended to produce the highest multipliers. Multipliers produced by RIMS II (Regional Input-Output Multiplier System) were shown to be somewhat higher 
(5-10\%) than those produced on the basis of company survey data (Lynch 2000).

Models of this type demand a certain amount of publicly-available data, which means that they can only be used in certain countries. Such models are based on inter-industry input-output matrices and assume that general relationships can be applied to specific companies in specific regions.

Survey-based research involving real companies in a specific area is quite different. The level of detail attainable in this multiplier calculation approach can be illustrated using the example of the impact of companies located in a Special Economic Zone (SEZ) in the town of Mielec in southern Poland (Domański et al. 2005). The magnitude of the multiplier effect was expressed in terms of the number of jobs created in Mielec poviat. The aforesaid jobs exist largely because they serve the needs of the SEZ companies (supply-side effects) and their employees (income effects).

The measurement of supply-side multiplier effects includes two essential stages: 1) identification of companies that deliver semi-finished goods and services to business entities that generate multiplier effects, and 2) determination of the extent to which their business depends on the aforesaid entities (customers). Data were collected from companies doing business in the Mielec SEZ as well as from their suppliers. The former made available information on the firms that supply them with materials and services. Companies doing business in Mielec poviat - but outside the SEZ - were asked to participate in a survey and identify the extent to which their revenue depended on SEZ customers. The survey also asked non-SEZ companies to indicate their percentage of jobs associated with meeting the needs of SEZ customers. Moreover, interviews were conducted with managers at major companies in Mielec poviat. The companies selected were ones that were deemed to be most likely affected by the SEZ companies. Survey participants were asked to play the role of experts estimating the number of business entities benefiting from collaboration with the SEZ companies and the number of jobs created as a result of the aforesaid collaboration. Hence, estimates of supply-side multiplier effects were based on both suppliers and custom- ers, which made it possible to verify the accuracy of the results.

The measurement of income-type multiplier effects requires the following data: 1) net income of employees, 2) household savings rate, 3) household expenditure structure, 4) the geographic area where consumer needs are met (local or regional), and 5) relationship between the revenue of business entities and the number of their employees. Salary data were obtained directly from the SEZ companies as well as from annual financial reports published by Monitor Polski B. Household expenditure data were obtained from GUS - Poland's Central Statistical Office. The degree to which demand is met locally was calculated for each type of economic activity on the basis of employee residency data, type of economic activity, and the spatial reach of each given service. Employee net income less savings constitutes consumer spending funds (disposable income), which can be thought of as potential revenue by business entities in trade and services. Household spending data can be used to calculate business revenues that different types of industries can expect. An income-based calculation affords a multiplier effect expressed in terms of money. In order to calculate multiplier effects in terms of the number of jobs, labour costs must be properly assigned to each type of consumer sector. When the cost of one job in a given industry is known (GUS data), the number of full-time jobs can then be calculated.

First-order income effects were calculated as described above. Income effects are also generated by suppliers' employees whose jobs have been created as a result of supply-side effects. Furthermore, individuals working for companies that serve consumer needs generate consumer demand themselves. This leads to second-order multiplier effects and third-order multiplier effects and so on - until the power of the effect approaches zero. The consumer service sector itself generates supply-side multiplier effects.

The method used by the authors is based on both information acquired in field research and data published by government sources and other institutions. The method is very labour-intensive and relies on collaboration with a large number of business entities in the study area. 


\section{Empirical studies of local and regional multiplier effects}

\section{Previous research}

The magnitude of multiplier effects varies substantially depending on their trigger and location. According to Weisbrod \& Weisbrod (1997), multiplier effects for most types of industries range between 1.5 and 2.0 at a large city level, 2.0 and 2.5 at a state level, and 2.5 and 3.0 at a national (USA) level. Isard \& Kuenne (1953) estimated the multiplier effect for the total impact of an increase in steel, metal and machine manufacturing industries on employment in the New York - Philadelphia economy to be 1.79 in 1953. Mulkey \& Hodges (2003) have shown that total multiplier effects in the United States calculated using IMPLAN software range between 1.5 and 2.5. The multiplier effect for a hypothetical new IT company in a rural part of Florida has been calculated to be 1.31 in terms of income and 1.30 in terms of employment - both after two years. Harris et al. (2003) have shown that the expansion of the healthcare system in Carson City, Nevada, has created 0.49 additional jobs for every new healthcare job (multiplier $=1.49$ ) as well as 35 cents of additional revenue for every dollar of new revenue in the healthcare sector (multiplier $=1.35$ ). Multiplier effects calculated using the REMI Model for another county in Nevada ranged from 1.2 to 1.5 for most industries (Rickman \& Schwer 1995). Barford (1938) analysed multiplier effects for an oil refinery in the Danish city of Aarhus and found the general income multiplier to be 1.27. Wiedermann (2006) used a method similar to that described earlier for the Polish town of Mielec when analysing multiplier effects for the automotive industry in Silesian voivodeship (Poland) and calculated the multiplier effect at 1.30 .

Multiplier effects tend to be stronger in services than in the manufacturing sector. This is also true in the case of an expanding manufacturing industry. Isard and Kuenne (1953) illustrated this key point using growth in the steel, metal, and machine manufacturing industries. They were able to show that the resulting growth in the service sector was almost twice that in the manufacturing sector in terms of the number of jobs.
A pioneering research in the field of impact of large firms in Poland has been done by Stryjakiewicz and colleagues (2004) on the economic impact of GlaxoSmithKline Pharmaceuticals (GSK). The study identified the location of its suppliers of raw materials, semi-finished goods, and services. The suppliers were also interviewed. The research results were used to establish the strength of the economic linkages between the surveyed companies and GSK as measured by the percentage of employees collaborating with GSK in one form or another and the suppliers' share of revenues originating from GSK. The average percentage of employees associated with GSK-related work was found to be twice as large among service providers as among suppliers of raw materials and semi-finished goods. The authors of the study did not evaluate the magnitude of multiplier effects in this case.

The local magnitude of multiplier effects depends on company-specific characteristics as well as the very nature of a company's economic activity (industry type). Other important factors to be considered include characteristics of a city or region.

Local companies tend to possess extensive local linkages resulting in stronger local multiplier effects than large companies doing business in many different regions and countries (Domański 2001). Local supply-side effects are normally stronger with companies that have been doing business in a certain area for a longer period of time. Multiplier effects resulting from the purchase of services tend to be more locally oriented than those resulting from buying manufacturing goods. Local and regional companies are far better equipped to render services than deliver specialised semi-finished goods and parts that are normally manufactured by a limited number of companies at a national or even global scale.

Greater local containment of supply-side multiplier effects (less trickling out of the area) can be observed in large cities as well as better developed cities and regions. The degree of diversification of the local and regional economy is an important consideration in this case, as it is related to the level of economic development of the area.

The most local of multiplier effects are naturally income-type effects, which are generated 
by employee wages and salaries. The strength of these effects is derived from the number of jobs available and pay levels, while their spatial distribution closely mirrors employees' places of residence. An economic activity that involves wellpaid specialists produces stronger multiplier effects than one involving less qualified personnel and lower pay. It must be noted, however, that well-paid individuals may spend more of their income on higher-order goods and services that may not be readily available in the local market. As in the case of supply-side effects, larger and more developed cities and regions create more opportunities to meet consumer needs locally.

\section{Mielec case study}

A comprehensive research study of multiplier effects was conducted for companies that had decided to open manufacturing facilities in the Special Economic Zone (SEZ) in the Polish town of Mielec (Domański et al. 2005). Supply-side multiplier effects associated with the SEZ companies were analysed, as were those associated with the growth of local companies that serve the consumer needs of SEZ employees.

The Mielec SEZ was found to create 4,950 additional jobs at a national scale (outside the zone). Thus, the overall multiplier effect of the economic trigger $(8,981$ new jobs created in the SEZ) was calculated to be 1.55 . The multiplier effect in Mielec poviat itself was estimated to create an additional 3,126 jobs. Hence, the local multiplier effect rooted in the SEZ was 1.35. The study did not consider indirect effects associated with the zone's impact on the town's new image, which may attract new customers who desire Mielecmade products and services. If such indirect effects were to be considered, the local multiplier effect could be as large as 1.40 .

Supply-side effects in the local economy tend to be almost twice as strong as income effects. When total multiplier effects are considered at a national scale, supply-side effects outweigh income effects even more.

An analysis of the distribution of local multiplier effects by industry indicates that services capture $85 \%$ of the measured effects in terms of employment. This is the result of strong supplyside effects driven by the service sector catering to the needs of the SEZ companies as well as income effects. The largest number of SEZ-related jobs created in the town of Mielec and in adjacent communes are associated with retailing and wholesaling $(24 \%)$ and transportation (22\%), followed by construction (13\%), security services, and maintenance (12\%). The local processing industry gained over $8 \%$ of new SEZ-related jobs, while the water and energy industry gained $6 \%$. The multiplier effect for manufacturing-type business entities is a mere 1.038 , or 38 new jobs per 1,000 new jobs created in the Special Economic Zone.

Sixty three percent of Mielec SEZ-related multiplier effects can be found at the local scale (Mielec poviat). The percentage varies for different types of multiplier effects. The largest percentage of local-scale effects (about 75\%) applies to income effects associated with the provision of goods and services to employees of companies doing business in the Mielec SEZ. In the case of supply-side effects associated with services rendered to the SEZ companies themselves, the local-scale effect can be gauged at over $60 \%$. SEZ needs such as water and energy are provided by local companies in Mielec poviat, while only 15\% of raw materials, semi-finished goods, and parts are provided to the SEZ firms by Mielec poviat companies.

In general, the case of Mielec poviat shows that the strength and extent of the impact of new manufacturing facilities depend first and foremost on the size and origin of the business and also on the type of industry. Company size determines its supply needs and the resulting strength of the supply-side multiplier effect. It also determines the quantity of income that reaches the local economy via employee salaries. It has been shown that local companies - both small and medium-sized - possess the strongest local economic linkages. Large non-local companies can possess a variety of outsourcing strategies. Companies of this type often take advantage of services rendered by providers located near their corporate headquarters. It is also often the case that a large company will outsource all of the needs of its daughter companies and affiliates in various regions and countries to one service provider.

The case of Mielec poviat clearly suggests that local supply-side multiplier effects are most 
often concentrated in the service sector. This is also true in the case of multiplier effects generated by manufacturing facilities. Hence, it is wrong to conclude that local or regional multiplier effects are weak on the basis of an analysis of the supply of goods alone.

The impact of the local characteristics can be detected in the degree to which additional demand can be met, which is how multiplier effects can be taken advantage of. In the case of a medium-sized town such as Mielec, most basic services are provided locally or at best from within the region. This is true of sales, maintenance, security services, transportation, and auto repair. The ability of Mielec to capture multiplier effects resulting from more specialised economic activity is usually limited, although it can be surprisingly substantial in some areas for a town of this size. This is especially true of local companies that maintain production lines at large SEZ companies. It is also true of local companies that specialise in the manufacturing of tools, mechanical equipment, and metal products. Such local specialisation is associated with manufacturing traditions created over the years by the WSK PZLMielec manufacturing facility. This suggests that local human capital and entrepreneurship are also important factors in a city or region's ability to capture multiplier effects.

\section{Weaknesses and difficulties associated with multiplier effect research}

An aggregate view of multiplier effects in terms of economic base theory is undoubtedly a severely simplified one. This type of view does not take the complexity of a city or region's economy and its internal linkages into account. It also ignores the non-homogeneous nature of external markets and unique interregional linkages.

The input-output approach has its own set of limitations. General models tend to be developed for large geographic areas and when the resulting inter-industry linkages are applied to individual business entities in specific cities or regions, they often do not take into account differences resulting from economies of scale. Survey research is one type of solution to this problem. However, even survey research usually does not take into account issues such as changes in pay levels, productivity, and costs of doing business, which affect the economic attractiveness of a given city or region.

Both leading measures of multiplier effects - number of jobs and income - have a number of limitations. The key weakness of the former is that it ignores differences in the quality of jobs and employee productivity across different industries. The key weakness of the latter approach is its inability to differentiate high value-added activity from low value-added activity.

Some authors question the very purpose of multiplier effect research since the aforesaid effects change over time as a result of dynamic inter-company and inter-industry linkages. Some have argued that any analysis of multiplier effects delivers only short-term knowledge (e.g. Smith 1981).

The measurement of multiplier effects is undoubtedly associated with a number of technical difficulties and demands several simplifying assumptions. Yet, simplifications of all sorts are a characteristic feature of all attempts to quantify highly complex economic processes taking place at a local or regional scale. It appears, however, that the reason why empirical studies of the strength and geographic range of multiplier effects are not undertaken very often has little to do with the weaknesses and technical difficulties inherent in the process, but rather with the labour-intensive nature of such research. Research of this type usually cannot be performed by one person alone.

It is important to point out the existence of certain 'traps' associated with the measurement of multiplier effects. It is widely assumed that the arrival of a new type of economic activity or an increase in the level of an existing one generates positive multiplier effects in the local economy. A decrease in the level of an existing economic activity is believed to generate negative effects. The first assumption implies tacit agreement that a new type of economic activity or an increase in the level of an existing one does not compete with the existing business entities in the local market. The arrival of new entities can generate both positive and negative multiplier effects in some cases. Some local businesses may be pushed out of the market or their share of the market may 
become markedly smaller. Retailing is a good example of this type of situation. The net multiplier effect is the difference between new demand and new employment generated by the incoming business entity and the resulting decrease in revenue or employment at other local businesses. The calculation of the net effect is very complicated, especially given that the end result will be different for every geographic scale selected. For example, the multiplier effect may be positive at a national scale, but clearly negative in a given geographic area. The same is true in the opposite case. If a certain type of economic activity suffers a decline in a certain city or region, new business entities may be drawn to that geographic area and partially or fully compensate for that decline, e.g. new footwear producers were established in Nowy Targ and its environs after the fall of the large state-owned factory in the 1990s.

It is very important to properly define the geographic area affected by multiplier effects. Whether something is treated as a multiplier effect or not will depend on the geographic scale assumed. The same is true of whether something is viewed as a positive or a negative effect. For example, special economic zones can help suppliers grow in one town at the expense of growth in another town. Such a multiplier effect will be treated as a positive one in the first town, but may not be viewed as being positive at a regional scale.

\section{Final discussion}

The mass media and political figures tend to overestimate the economic power of multiplier effects. When BMW announced plans to build a new plant in South Carolina (1,900 new jobs), state officials predicted that over 10,000 new jobs would be created as a result. This would yield a multiplier of 5.33. The multiplier calculated using RIMS II was no greater than 2.55 (Connaughton \& Madsen 2001). Three years after the plant went on line, the boom in suppliers' business predicted by the state officials had not materialised (Philips, Hamden \& Lopez 2004). In Poland, it was believed that one new job in an automotive assembly plant would create five to seven jobs at suppliers. It was also believed that one new job in a hypermarket would create between two and five new jobs in its immediate surroundings. An IMPLAN simulation for a hypermarket with 500 employees in Washington County produced a multiplier of 1.3 without considering possible negative effects of local retailers pushed out of the market.

The views described above tend to be rooted in an insufficient amount of empirical data available as well as the belief that everything associated with a given new economic activity can be treated as a multiplier effect. Thus, the role of a certain economic activity $X$ in a local economy as measured by the number of jobs or income directly or indirectly supported by this activity (gross effect), can be confused with its net impact as measured by the expansion or contraction of various economic activities in the area driven by an increase or decrease in activity X, i.e. multiplier effects (Weisbrod \& Weisbrod 1997).

The real magnitude of properly defined local multiplier effects is usually between 1.20 and 1.50 based on empirical data. Multipliers calculated for Mielec poviat are also within this range (1.35-1.40). Regional multipliers have been found to be greater.

Regardless of the tendency to overestimate the power of multiplier effects, the significance of multiplier effects in local and regional economies is nevertheless difficult to overestimate. A substantial body of evidence in favour of multiplier effects lies in the history of socialist economies, which aimed to replace market mechanisms with administrative allocation of resources, a strategy that eliminated multiplier effects. The absence of multiplier effects in a supply-driven economy as opposed to a demand-driven economy - was one of a number of reasons why the creation of new business facilities led to an economic imbalance in cities and regions (Domański 1997). Other side effects of this type of economic strategy included a shortage of consumer services and services designed to support key sectors of industry.

The importance of multiplier effects lies in their very nature: they are an expression of the linkages inherent in local and regional economies. A study of the strength, industry structure, spatial distribution, and key drivers of these effects can serve the following purposes: 
- it can help understand the growth mechanisms underlying local and regional economies,

- it can help evaluate the advantages and disadvantages associated with foreign investment as well as the effectiveness of regional economic policy that may include special economic zones (ex ante or ex post), and

- it can help evaluate economic threats associated with the liquidation or contraction of a given economic activity in towns and regions, e.g. bankruptcy or relocation.

From a geographic point of view, the spatial characteristics of multiplier effects are of particular interest. This includes the geographic range of multiplier effects at a local or regional scale as well as the factors that determine this range. In addition to differences resulting from the very nature of a given economic activity or a company, characteristics unique to a given city or region play an important role. Such characteristics determine the ability of the city or region to capture multiplier effects by satisfying new demand. This ability tends to grow with the size of the city or region. In addition to size, the position of the city in the urban hierarchy is also an important factor here. Better developed cities and regions possess more diversified economies that allow them to capture multiplier effects better. The spillover of multiplier effects out of a city or region is inversely proportional to the size of the city or region. The smaller the city or region, the more likely it is that multiplier effects will escape the local economy. An understanding of the degree to which multiplier effects are local can only be achieved in conjunction with research on urban hierarchy.

One of the fundamental challenges in multiplier effect research is going beyond the measurement of short-term effects. More research is needed on the temporal aspects of multiplier effects in order to identify those effects that tend to last longer. Another research goal that deserves attention is the development of prognostic tools for multiplier effects based on an understanding of the factors that attract or repel different types of economic activity to cities and regions. Undoubtedly, multiplier effects need to be analysed further both at a theoretical level and a technical level rooted in empirical analysis.

\section{References}

AleXander J. W., 1954. The basic-nonbasic concept of urban economic functions. Economic Geography 30: 246-261.

BARFORD B., 1938. Local economic effects of a large scale industrial undertaking. Munksgaard, Copenhagen.

Connaughton J. E. \& Madsen R. A., 2001. Assessment of economic impact studies: the cases of BMW and Mercedes-Benz. Review of Regional Studies 31: 293-303.

DomAŃsKi B., 1997. Industrial control over the socialist town. Benevolence or exploitation? Praeger, Westport, CT.

DOMAŃSKI B., 2001. Kapitat zagraniczny w przemyśle Polski. Prawidłowości rozmieszczenia, uwarunkowania i skutki (Foreign capital in Polish manufacturing and mining). Uniwersytet Jagielloński, Instytut Geografii i Gospodarki Przestrzennej, Kraków.

Domański B., Gwosdz K., HuculaK M. \& Wiedermann K., 2005. Oddziaływanie SSE Euro-Park Mielec na otoczenie lokalne. Powiązania firm i efekty mnożnikowe (Impact of the Euro-Park Mielec SEZ on its local environment. Company linkages and multiplier effects). In: B. Domański \& K. Gwosdz (eds), Dziesięć lat doświadczeń pierwszej polskiej specjalnej strefy ekonomicznej. Mielec 1995-2005. Instytut Geografii i Gospodarki Przestrzennej UJ i ARP O. Mielec, Kraków-Mielec, 89-131.

Harris T., Griswold T., Segurson M., Packham J. \& Ford C., 2003. Economic impact and linkages of the local health sector on the economy of Carson City, Nevada, 2000. Department of Resource Economics, University of Nevada, Reno.

Hoyт H., 1949. The economic base of the Brockton. Massachusetts Area, Brockton, Mass.

IsARD W., 1960. Methods of regional analysis. MIT, Cambridge, Mass.

IsARD W. \& KuENNE R.E., 1953. The impact of steel upon the greater New York - Philadelphia industrial region: A study in agglomeration projection. Review of Economics and Statistics 35: 289-301.

Lloyd P. \& Dicken P., 1977. Location in space: A theoretical approach to economic geography. Harper and Row, London.

LYNCH T., 2000. Analyzing the economic impact of transportation projects using RIMS II, IMPLAN and REMI. Florida State University, Tallahassee.

MilleR R. \& BLAIR P., 1985. Input-output analysis: foundations and extensions. Prentice Hall, Englewood Cliffs, NJ.

MulKey D. \& Hodges A., 2003. Using Implan to assess local economic impact. University of Florida, Gainesville, http:/ / edis.ifas.ufl.edu. 2008.07.16.

Philips K., Hamden K. \& Lopez E., 2004. Gauging the impact of the San Antonio Toyota plant. Vista-South Texas Economic Trends and Issues, 1-4.

PROPST D., 2000. Use of IMPLAN to assess economic impacts of recreation and tourism: Chronology and trends. www.prr. msu.edu/trends2000/papers_pdf/propst_implan.pdf. 2008.04.14.

RickMAN D. \& SCHWER K., 1995. A comparison of the multipliers of IMPLAN, REMI and RIMS II: Benchmarking ready-made models for comparison. Annals of Regional Science 29: 363-374. 
Sмітн D.M., 1981. Industrial location: An economic-geographical analysis. John Wiley and Sons, New York.

StRYJAKIEWICZ T. (ed.), 2004. Wptyw inwestorów zagranicznych na rozwój regionalny i lokalny na przykładzie GlaxoSmithKline Pharmaceuticals S.A. w Poznaniu (Impact of foreign investors on regional and local development: The case of GlaxoSmithKline Pharmaceuticals in Poznań). Bogucki Wydawnictwo Naukowe, Poznań.

Weisbrod G. \& WeisBrod B., 1997. Measuring economic impacts of projects and programs. Economic Development
Research Group, 1-11, www.edrgroup.com/pages/pdf/ Econ-Impact-Primer.pdf. 2008.05.16.

WiedermanN K., 2006. Czynniki i skutki rozwoju przemystu motoryzacyjnego w skali lokalnej i regionalnej na przykładzie województwa ślaskiego (Factors and effects of the development of automotive industry at the local and regional scale: The case of Silesian voivodeship). Ph.D. thesis, Institute of Geography and Spatial Management, Jagiellonian University, Kraków. 